\title{
Re-Reading Student Texts: Intertextuality and Constructions of Self and Other in the Contact Zone
}

\author{
K a r e n Rodrigue z \\ Council on International Educational Exchange, Guanajuato, Mexico
}

A commitment to intertextuality is also a commitment to difference and to becoming Other. The politics of intertextuality and the postmodern are radical and concerned with resistance and change. (Fox, 1995)

... the act of reading plunges us into a network of textual relations. (Allen, 2000, p. 1).

\section{Introd uction}

I have long argued that there is a need in study abroad to widen the range of theoretical approaches we use to think about the encounters with difference our profession makes possible. The reliance upon a few limited models and approaches, as good as they may be, leads us towards the danger of reproducing ever-more refined interpretations within a single paradigm that often reinforces a very American binary mode of thinking about difference. These patterned ways of thinking tend to silence other ways of interpreting cultural difference and to ignore the fact that others at the sites we go to are also producers and consumers of texts about which they too are trying to figure out difference. I would like to suggest in this article that if we moved beyond our usual readings of what goes on in a study abroad experience we could make a modest move against logocentrism, which gets at the heart of what international education is ideally all about.

This article examines a student poem about a common gendered experience in Guanajuato, Mexico, which was written by a student in a creative writing group I led during a one-semester study abroad program I direct for CIEE (Council on International Educational Exchange). ${ }^{1}$ The article posits Guanajuato as a contact zone where Mexican culture and US culture meet in myriad ways on a daily basis. It introduces the notion of intertextuality to complicate the typical way we might read the text. After looking at one possible US interpretation 
that might be given to this piece, it tries not to discredit it, but to de-privilege it as the only possible interpretation. The article does this first by opening up several interpretive possibilities within the text and, second, by taking the student text into the wider interpretive domain to look at what the local other is also expressing textually in the midst of intercultural contact. It considers two types of local texts: a t-shirt genre that is currently popular and the ubiquitous bar flyer handed out on the streets of Guanajuato.

I attempt to show that everyone in this contact zone resists being constructed by the other, and that everyone writes his or her identity into the social context. By considering the student text from another perspective, and from a less common theoretical point of view, the article argues that we can destabilize our own complacent way of knowing, bring other perspectives into our understanding, and model the type of learning in which we hope our students engage.

\section{Guanajuato as a Contact Zone}

It is helpful to imagine Guanajuato as what Mary Louise Pratt defines as a "contact zone," a social space "where cultures meet, clash, and grapple with each other, often in contexts of highly asymmetrical relations of power (1999, para.7)." ${ }^{2}$ Located in the middle of Mexico, Guanajuato does not border the US; however, it constitutes one of many sites in which US and Mexican cultures are in constant dialogue. Despite its outwardly traditional, tranquil appearance, Guanajuato, a small university city of about 75,000 firmly rooted in provincia, has for the past 30-odd years been a nexus of student exchanges, tourism, and migration. ${ }^{3}$ Cable TV, US movies, and the internet are also available to most local residents. Cultures are thus meeting through the media and face-to-face interactions in overlapping and complex ways everyday.

Power relations in Guanajuato, as in any contact zone, are uneven and unsettled. They are shot through with gender, class, ethnicity and nationality in ways that have both domestic and global dimensions. To conceptualize power immediately in flat terms of dominant versus non-dominant would constitute a gross oversimplification of onsite realities. Our students travel from a powerful point of origin, the US. In Mexico power is associated with whiteness, wealth, foreignness, and masculinity, yet not all study abroad students have all of these characteristics, if indeed they have any of them. Students will thus both exert power and experience disempowerment based on any number of factors and based on with whom who they are in contact. What we see in the contact zone, then, is not a simple struggle between the powerful and the powerless, but rather, a range of people resisting othering processes that emanate from distinct cultural, 
political and historical processes at the local, domestic, binational and global levels. ${ }^{4}$ Everyone is representing and being represented, and the dynamics of the struggle over representations thus becomes particularly multi-layered

These struggles have a textual dimension as well, and texts can be seen as both products and producers of local social realities. According to Pratt, several characteristic writing strategies in contact zone texts include autoethnography, transculturation, critique and denunciation, collaboration and mediation, bilingualism, imaginary dialogue, and vernacular expression (1999). When these techniques are used, she argues that different readers will interpret a contact zone text in distinct ways hat relate to their levels of intercultural competence and degree of bilingualism and biculturalism.

While student experiences and writing about them take place in real, onsite spaces of contact and conflict, one question that has not been considered in much depth is that of how a given piece of writing relates to the dynamics of the local contact zone. We tend, and I specifically include myself here, to extract student writing from the local context as if it were any other cultural artifact or souvenir. Moreover, we tend to analyze the writing in terms of our own models, theories, and ideological positions that are still heavily tied to US academic culture. No matter how critical or liberal our home-campus academic culture may be, this has the effect 1) of silencing the other (textual) realities that exist onsite and, 2) of ignoring the dialogic relationships at work within and outside of the text.

Following this idea, if we take as our point of departure that interpretation is situated within larger sociocultural contexts and discourses that sketch out certain well-trod routes towards understanding, then one might ask what would happen if instead of exporting study abroad texts from foreign sites to the US (or the US discursive realm) for interpretation, we kept them in context and explored other potential interpretations in dialogue with the local context and with other local texts.

\section{The Concept of Intertextuality}

As we attempt to bring a text back into the context in which it was produced, the notion of intertextuality, a tool used frequently in critical discourse analysis and in literary theory, proves very useful. Intertextuality refers to the resonances that all texts have with previous texts, be they written, oral, visual, sensual, etc. These relationships are sometimes explicit, for example when other texts are quoted or alluded to directly. They can also be indirect and even unconscious because previous texts influence, establish genre conventions, and make 
culturally-socially sanctioned patterns of word use available to us (Fairclough, 2003; Gee, 1999). While the term intertextuality is credited to Julia Kristeva, feminist psychoanalyst and philosopher, her perspective is highly influenced by Mikhail Bakhtin, whose ideas she introduced to the French theoretical circle in the late 60's as structuralism was beginning to yield to emerging post-structuralist theories.

The main ideas that originate with Bakhtin and that are then developed by Kristeva include the following assertions. First, all utterances are seen as linked to previous ones. ${ }^{5}$ In this sense, our words are never purely our own, and indeed, they contain traces of others since all of our words relate to previous words formed within our cultural and historically-situated interactions with language. This is not so unusual of an idea since as Roland Barthes reminds us, the etymological roots of text lie in "textile," something woven together from already existing strands (1977b). Each text thus contains a plurality of texts within, some of whose resonances are explicit and some not. This means that nothing is truly autonomous or original.

This notion is important for how we look at study abroad texts because a good part of student writing will be linked to their previous reading and writing experiences in the US. This means that there are cultural histories embedded not only in students themselves, but also in the words, and situated understandings of these words, that they use. If we look carefully at the language students use, we see how students are grounded in English in ways that relate to gender, class, ethnicity, first language and so on. Furthermore, and more directly related to this article, once students are involved in onsite encounters with different languages and words that come from different discourses about cultural difference and identity, we may find signs of their changing ideas at this very micro level. By studying abroad, students become exposed to new discursive possibilities.

If no utterance or text is completely pure, then all texts exist in dialogic relation with one another, which means that they connect across vastly different ways of knowing. ${ }^{6}$ This approach locates the meaning of a text within the larger sociohistorical context in which it is produced, which opens the way for multiple meanings if one reads it from different social, cultural, or historical positions. More radically, if a text is always dialogic and heteroglossic, Kristeva argues that this challenges Aristotle's assertion that nothing can be both A and not-A (Allen, 2000 , p. 43).. In this sense, depending upon the social and historical setting, or upon viewpoint and context, a text can indeed be two or more things. She affirms that intertextuality is "... language which because of its embodiment of otherness is against, beyond, and resistant to monologism” (Allen, 2000, p. 45). 
This is an exciting concept for study abroad, which tends to conceive of self and other in oppositional terms, when in reality students are often two or more people and mean different things to different others. Within an intertextual understanding, study abroad students can be read as both native and foreign, white and not-white, American or not, depending on who is doing the viewing. Local community members can also embody various identities at once, which fits the case of Guanajuato, where locals also form their identities within and across competing categories.

If texts are opened to multiple interpretations, the reader determines (one) meaning and the author is therefore dethroned from having authority over the "real" meaning of a work. This challenges author-centered analysis that has prevailed since the Renaissance, in which the individual writer is viewed as authoritative and unique. In a reader-oriented model, which was inaugurated most dramatically with Barthes's 1977 essay, Death of the Author, the author is made less monolithic, and seen as textually and socially constituted himself (or influenced by other prior texts and discourses), and less necessary for the interpretation of the text.

Although this article emphasizes the importance of the reader, since this opens up texts to other interpretations, it does not go as far as Barthes does in dismissing the author. Students need to break out of their own silence and various marginalized positions in order to gain a more multi-faceted voice in the construction of knowledge. However, there are some interesting implications in Barthes' line of thought that resonate with my own recent concerns. Just as we have tended to center analysis and origins of truth on the author, in my own teaching and program work, following critical pedagogy (e.g. Freire, Shor), I've tended to center upon the student, emphasizing the individual experience about which each student is the expert knower/interpreter. While this empowers the student, I wonder if I've gone too far in making the student view too central, foregrounding the personal experience at the expense of a more dialogic orientation that would include the other more fully. This sticky question parallels my concerns about interpreting student writing and onsite experiences only in terms of US academic discourse.. While, again, we won't ignore the individual here in an effort to make the diversity and heterogeneity of "the" study abroad student more visible, there exists a tension here that is worth acknowledging and a warning to avoid reifying the individual experience at the expense of the other's active participation in it. ${ }^{7}$

In sum, a writer evokes his or her representation and worldview, and different writers use the same discursive resources of the contact zone to produce 
highly varied texts that will then be read differently by different readers from multiple points in the contact zone. All of this allows us to envision a text as a micro-level contact zone, a site of conflict where meaning is contested, negotiated and created. As Barthes writes, "A text... is a multidimensional space in which a variety of writings, none of them original, blend and clash" (1977a, p. 21). This is where past meets present, outside meets inside, the social meets the personal. Texts from the contact zone thus serve as negotiation sites from which potentially transformative representations of the world may emerge.

\section{M e thodology}

In order to analyze a text within this framework, Kristeva (1980) offers a useful model. Any text, she says, can be analyzed along two axes. The horizontal axis runs from author to reader, or from writing subject to addressee. The vertical axis runs from the focus text to other texts, drawing each utterance into the wider (or infinite) intertextual realm. This article works in both directions, opening the focus text, the student poem, towards other local readers and other texts situated in the local and current context, and looking for different interpretations. It is important, however, to stress that intertextuality is not triangulation (Collier, 2001, p. 10). Rather, it involves a dialogue across perspectives and epistemological traditions. The purpose then, is not to look for evidence that will prove the validity of the focus text or to argue for one coherent/consistent interpretation. Rather, the purpose is to allow other co-texts in the contact zone to speak and to take part in the dialogue.

The following student poem will be analyzed, a poem written in response to having received one too many catcalls or sexual comments out on the street. 


\section{Sincerely Yours}

I'd like to smile and thank you for the crude comment sopping with your self satisfaction in hopes that it would make me all wet. So thank you random car driver, casual spectator and occasional "wasted" man. I relish the fact you think my ass is great as cherry pie and am more than flattered that you would also like a piece of it. But even more, you're right on the money because my body does move like that in the sack. What's that? Yes, I just so happen to gyrate better than most Maytags. I'm a regular Stretch Armstrong if that's what you're thinking. But enough about me. I'd like to return the flattery of filth favor in hopes it'll do the same for you. I could tell you something nice like "the sparkle of your smile made me think of a freshly landed comet," but why say something like that when I could really get my kicks from saying that me and your malodorous man-sex would be some romp in the hay. Or better yet, that I'm just plain hot over the thought of your bulge as you walk past. But wait, I think you'll really like this one; that the brillo pad you have for chest hair would virtually do a number on my pots and pans, if you know what I mean. Yeah that's what I'm talking about. I had a feeling you might like the mutual masturbation of our exchange because for once, I sure did.

\section{"Sincerely Yours": I nitial Re ading}

This poem was written for a poetry group I led with my Fall 2004 students. The author was a student at Sarah Lawrence College. She is a first-generation college-goer from Taos, New Mexico, of mixed ethnic background. An initial reading within existing US discourse about cultural difference and study abroad would most likely interpret this poem as a much deserved, long held-back response to what one could certainly label as a form of sexual harassment that our female students encounter on the streets in Latin America and, perhaps, elsewhere. As an onsite director, I could also envision a reaction that would applaud this as both a safer alternative than using these words in an actual direct verbal confrontation and as a creative and intellectual means of processing the experience.

Many would probably read the poem as yet another sign that machismo is ever-present in Latin America, one of the negative experiences that our women students are forced to confront abroad. Both members of our professional community and students have situated understandings of "machismo," a word that exists in everyday US discourse. These understandings tend to be rooted in fairly ahistorical, stereotypical cultural views, and most uses of 
the term signal machismo as simply a Mexican brand of sexism that is always viewed as more pernicious than its US counterpart, which, correspondingly, is rarely acknowledged. Consciously or unconsciously, we have prior texts in our minds when we read this, which include stereotypes, movie images, political texts, and the few but much needed studies that have been done on gender and study abroad (Polyani, 1995; Twombly, 1995; Talburt and Stewart, 1999; Anderson, 2003).

This is not to suggest that everyone would read the poem in the same way, but it is an attempt to situate one particular interpretation within a common framework most of us are familiar with. This is not an interpretation without value. Recognizing that gender is a factor that differentiates the study abroad experience works against other discourses in study abroad that do not recognize heterogeneity among our student participants This, then, leads to obvious problems in practice in the areas of curriculum, advising, and evaluating whether or not the experiences we help to create actually accomplish what we intend. And certainly the meaning that the student intended to evoke in the poem could fit this interpretation as well.

However, despite the fact (or because) we may be comfortable with this interpretation, this is a rather limited position from which to develop a final stance, and one that does not include any consideration of other meanings that exist within the text and between the text and other onsite phenomena. What follows is a microanalysis that destabilizes meaning within the poem and alludes to intertextuality within the text, and then a macroanalysis that looks at intertextuality beyond the poem and into the contact zone context of Guanajuato.

\section{The Text Itself: A Microanalysis}

In terms of genre, "Sincerely Yours" is a prose poem. The prose poem emerged publicly in 19th century France with the publication of Baudelaire's Paris Spleen and other contemporary work by Mallarmé and Rimbaud. Prose poetry offered a challenge both to poetry's conventions of meter and rhyme and to prose's less rhythmic, longer format, and eventually became its own genre, gaining strength first among the British Decadent writers, and then from US "language poetry" writers of the 60's and 70's.

Prose poetry thus represents a crossing of genres through which a third genre is produced and poetic parameters are redefined or recombined. We have from its beginnings, then, a genre that transcended tradition to become a new genre of its own. 
Not only is this piece a prose poem, but it falls also into another, more local, genre or "speech genre" (Bakhtin), the piropo. The piropo, which came to Mexico from Spain, was historically a chivalrous compliment offered orally from men to women, both in private and on the street, or in public situations where the two people did not necessarily know one another. In the last generation or so, it has evolved into a range of remarks that run from the traditional and absurdly romantic, such as "You must be an angel fallen from the sky," or "I wish I were cross-eyed so I could see you two times at once," to the downright lewd: "I've got two eggs for all that bacon" — which has a double sexual meaning in Spanish. These picturesque piropos blur into the final category of street comment: the nameless sexual remark that displays no poetic or creative elements whatsoever. In Guanajuato, this last set of remarks at the piropo margin has also become increasingly bilingual.

In the poem, our foreign female student, the poem's 'narrator' as I'll refer to her here, addresses an unnamed local man who represents piropo-using men-onthe-street in general. The man, the addressee, is not given a chance to respond. His voice is acknowledged and then essentially cut off by the speed of her talk, which does not permit interruption. This could be seen as a genre-level feature of prose poems since the foregoing of end stops or line shifts allows a certain speed to be built up. Certainly, this is not the expected response to a piropo: the man would most likely expect silence since these are not considered conversation openers, but one-way communications, and also because male-to-female comments of this nature are typically made at the moment of passing, at the moment when bodies are closest, and movement makes a face-to-face response impossible or, at best, difficult to engineer. The poem does reflect the characteristics of piropo-giving, however, since the man too is rendered voiceless.

As we read through the poem, we see that the narrator appropriates the piropo genre and the man's actual words. She also fires her own piropos at him in return. The poem thus is an act of transculturation, which Pratt (1999) defines as the use of cultural others' "materials" or discursive resources (as critical discourse analysts would refer to them) for highly self-constructing and oppositional purposes.

\section{Inside the Text}

There is much to analyze within this text; however, a few points stand out in particular. First, the narrator uses at least two social languages or voices as she speaks. The majority of words are informal, and some are decidedly non-academic ("in the sack," "get my kicks," "yeah"). Metaphors and similes relate to popular 
culture at a middle/working-class level ("romp in the hay," "Maytag," "Stretch Armstrong," "do a number," "pots and pans"). This language may stand out in my own reading since my interaction with Americans for the past nine years has been limited almost exclusively to college students, university professors, or international education administrators, who do not tend to use these words and references or at least not in the professional contexts in which we interact. On the other hand, other features of the text also signal the college-level speaker. There is complex sentence structure, and it is highly articulate with no ring of high schoollevel syntax or vocabulary. Even within sentences, one can observe the presence of several social languages at play (Gee), or a double-voiced discourse (Bakhtin), which points to an intertextuality at the micro-level since this speech is already appropriating existing expressions from several class and cultural positions.

Her word choice also makes the text recognizable, giving it what Barthes refers to as the "déjà lu" quality (1974). In effect, someone from the US can "get" this, and the strange is made familiar, although I will revisit this idea in a moment.

The repetition via synonyms ("random," "casual," "occasional") also help us locate the poem. They imply that he is about to "get it" for the rest of the men just like him, in the same way that she has had to "take it" for the rest of the women just like her. She is thus as random to him as he is to her, and this can be read as a move that evens out the playing field. While this is a specific verbal instance, there is no specificity attributed to the physical context; one cannot conjure up the exact setting, time of day, or locale, which has the effect of making the incident more generalizable.

Turning to the structure of the exchange, the narrator first acknowledges the addressee, and then takes her own turn at about the middle of the poem. This is signaled by the words, "But enough about me," which is an ironic or double-meaninged line since she is only now about to speak in her words instead of his quoted ones. She sets up a situation of mutual speaking and listening although the turns are clearly marked and divided. Indeed, the only "we" of the entire poem falls in the last line (implied only) with the "mutual masturbation" and the "our" of "our exchange." And while the man and the narrator are thus structurally put on the same footing, in the course of speaking back, she regains the upper hand.

Second, and more important for the purposes of this article, the poem does several things that re-center this experience as potentially not in Mexico. While the narrator cites the man's speech, which references the larger range of piropo texts available locally, he is quoted in cultural and literal translation. 
This could suggest previous knowledge of the subject at hand, which de-situates the behavior as exclusively a feature of this particular Mexican context. This is rarely acknowledged in discussions about this subject and, I would offer, probably reflects the current class orientation of most researchers/administrators who, as professionals on college campuses, are somewhat less likely to be involved in these sorts of encounters in the US. Nonetheless, being whistled at and commented on is not always a new experience for students and has everything to do with where they are from in class, ethnic, and regional terms. In fact, there is nothing in this poem that specifically signals Mexico at all, so the cultural "other" here is de-nationalized or "de-ethnic-ized." As such, although the poem can be read as referencing other onsite experiences, through the choice of language the poem can be as re-centered verbally and spatially not taking place in Guanajuato.

Adding to this potential interpretation is the fact that none of the comments that are attributed to the man have say anything about the narrator's foreignness, only about her identity as a woman. The student here appears to be "passing," assuming the identity of a local woman, the implications of which have not been considered in enough depth in studies on gender and study abroad. "As a liminal practice, passing disrupts binary views of self/other and us/them and calls our attention to the politics of identity that play out within adaptive processes and inter/cultural travel" (Moon, 2001: 219). The fact that the student passes thus further destabilizes the foreigner versus local construct. The narrator could indeed be aligned with other Mexican women on the street just as easily as she could be a female student from the US. In short, gender is in the foreground; ethnicity/nationality and class are all placed in the background. This begs the question of what Mexican women are doing textually within the area of Guanajuato, and how they might be responding to piropos.

In sum, within the poem we can observe several discursive resources that are intertextual and that are characteristic of contact zone writing. It is a parody, an appropriation of a genre, and an autoethnography of sorts, in that the narrator appropriates images of the female other made by the male self that has always occupied a relatively privileged position in Mexico, as in the rest of the world.

\section{Contexts and Co-texts: Macroanalysis}

Moving from the text into the larger domain of writing in Guanajuato, we find many local texts that are also resisting a wide range of othering processes and which expand our readings further. 


\section{“Naco" t-shirts}

One of the most common forms of popular expression in Mexico is the naco t-shirt. The word naco emerged in the 1970's from the longer "Totonaco" and was originally used as a derogatory race-based insult against Indians. It was also extended to include peasants and other non-modern figures during this period of oil-induced growth. Lomnitz-Adler observes that by the 80's and 90's, what was naco became "recognized as a characteristically urban aesthetic" (2001, p. 112). Recent writers in both English and Spanish, Ilan Stavans (1990) and Carlos Monsiváis (1997), have translated naco as kitsch (when referring to material things and taste) and, rather awkwardly, as tacky or gauche when referring to behavior. Naco things and actions have been linked to modernization and are viewed as failed attempts to pull off a full or convincing performance of modern identity (Lomnitz-Adler, 2001).

However, most recently, what is naco has gone from being vulgar and socially unacceptable to enjoying a certain vogue, most clearly summed up under one of its key slogans "Lo naco es chido" (being naco is cool). Even the word chido itself, once not spoken in mainstream/modern sectors, has become a ubiquitous albeit informal word in everyday discourse. Moreover, the naco t-shirt, a medium through which naco ideas are expressed, has taken on tremendous popularity, not only among the lower urban classes, but also among middle- and upper-class youth who do indeed have access to the trappings and experiences of modernity that the original nacos most definitely did not. ${ }^{8}$

The highly irreverent t-shirt slogans, which deploy a distinctively Mexican type of humor, can be categorized into several main themes. One category of shirts makes fun of how Mexican Spanish speakers pronounce English words that have come into daily usage. These one-word shirts include, for example: estaff (staff), los bitles (the Beatles), a pecsi (Pepsi) shirt that was discontinued after copyright issues with Pepsicola, diyei (D.J.), broder (bother). Another set of messages focus on the illegal immigration question. Both of these categories could be read both as affirmations of identity and proclamations of certain domestic socioeconomic realities that Mexico does not like to acknowledge, and of US discrimination that the US does not like to acknowledge.

Still another category of shirts takes on globalization and trade themes. These provide an example of what Monsiváis refers to as Mexico’s ability to “mexicanize her Americanization" (Joseph, Rubenstein, \& Zolov, 2001). One sees, for example, parodies of American brands and commercials such as Puma (Fuma, smoke), Disneyland (Chilangolandia, in Disney-esque lettering with little stars), of American institutions such as Alcoholics Anonymous (Alcólicos Aferrados, 
convinced alcoholics), television shows such as the Super Powerpuff Girls (Soy una de las chicas superpoderosas, I'm one of the superpowerpuff girls), and MasterCard commercials. Others refer to other phenomena of contact (Se habla español, Spanish spoken here; En vías de desarrollo, in the process of development).

Some critique domestic problems (Amo el ruido y el esmog, I love noise and smog; los ricos también roban, the rich also steal, which plays on the saying los chicos también lloran, boys also cry; no me asaltes soy obrero, don't assault me, I'm just a factory worker - meaning wages are so low I won't have any money) and also point to class identity in economic and popular culture terms (soy de sangre azul — cruz azul, I have blue blood- Blue Cross; ahora quién podrá defendernos, now who will defend us, said by the Chapulín Colorado, a television icon that has been around for decades).

In each of these categories, one sees a specifically Mexican humor. It is ironic and often self-deprecating and renewing at once, and an extremely popular discourse that has rarely seen much print exposure outside popular settings. This use of vernacular humor is one of Pratt's arts of the contact zone, and could be seen as a manifestation of mexicanidad/Mexican identity that emanates from below and persists in the face of globalization, migration, and increased media and real contact with the US, to resist being othered

\section{Naco shirts and the piropo-giver}

These t-shirts permit us to complicate or expand our views of the piropogiving man referred to in the student poem. Indeed, the t-shirt texts could well be his slogans. The piropo-giver in Guanajuato has not benefited from increased contact with the US. He is certainly not the host father or professor who makes money from this; nor is he a middle-class student who might gain friendship or sex from this. His very targeting of an American female, while not unrelated to gender - i.e. he picks the easiest entrée, the unprotected, weaker woman - is not exclusively an assertion of gender constructions. He could very well be seen as resisting the fact that he is not a beneficiary of American influences, and resisting US constructions of the 3rd world as feminine, through his own manipulation of a traditionally Mexican and masculine genre, the piropo.

\section{Naco shirts and young local women}

The same t-shirts take on a final category, that of gender, and this allows us to re-read local women as well. The naco t-shirt genre arguably has provided young women with a forum in which to turn traditional stereotypes and values on their head. These t-shirts provide textual messages that (loudly) resist traditional 
images of Mexican womanhood. While not all local groups, especially the older generations, are fans of the naco shirts, t-shirt wearers are not singled-out on the street, marginalized or demonized in any way. This would have been impossible even a decade ago. Let's take for example the following very common t-shirt in Guanajuato: "No soy virgin, pero hago milagros." (I'm not a virgin but I perform miracles) Through the shirt, the t-shirt-wearing girl resists being othered as a woman by Mexico's patriarchal society, and she also resists US constructions of Mexican women as passive, pure, and exceedingly traditional in terms of sexual values when compared to American women.

The tone of the first clause is openly assertive and defiant; the clause that one almost expects to follow is a challenging "y qué?" or "so what?" This could be interpreted as a move to reject openly the traditional framework so that young men not willing to enter into a more democratic or equal relationship need not pursue her or waste her time. And the "No soy virgin/I'm not a virgin" also references a distancing from the standard image of female perfection, the Virgen María, which breaks traditional mores. The second clause, "I perform miracles" is better explained in Spanish: the verb "hacer" means to make or to do. From a feminist standpoint, this marks a radical departure from the traditional woman as object — as "done to" - to woman as subject — literally, here is what I do. This is clearly an expression of empowerment, at least at the level of the public message the t-shirt sends out.

The interpretation becomes more complicated, however, as we read across other local texts. For example, according to a local Guanajuato psychologist specializing in women's studies, there is no systematic or permanent government program that addresses the topic of adolescent sexuality, beyond the biology class/ anatomy approach (Altamirano, personal communication, Oct. 25, 2005). ${ }^{9}$ In 2004, local newspapers and internet websites also simultaneously carried stories about the state's Health Minister, who did not approve one type of over-the-counter emergency contraception, and about the ongoing availability of similar overthe-counter medicines, information about which is well-publicized on Mexican websites. When one looks for texts that might educate the t-shirt wearing young woman (who may or may not read the newspaper and may or may not use the Internet depending on educational level, class status, etc.), there is the possibility that she enjoys a liberty that will be quickly cut short by a pregnancy.

Reinforcing the in-process nature of gender constructions is another local text being written by a woman who is in her sixties. She writes short stories about the young women who engage in rather anonymous sexual activity in the city's trademark alleyways (callejones) during the Cervantino International Festival of the 
Arts. She is documenting the trend of women taking home unplanned pregnancies as "souvenirs" from the Cervantino. Herein another text that testifies to the ambiguous and as-yet-unresolved nature of gender and identity in Guanajuato.

Previously, researchers and administrators in study abroad have found that female students placed in opposition the behavior of female American tourists and "traditional" local women, and have used this perceived difference in moral values or personal freedoms to at least partially account for the barriers they sometimes encounter when seeking out female friendships (Twombly, 1995).. While this may well hold true for many parts of the world, a look at other texts of the contact zone certainly encourages us to revisit these assumptions for Guanajuato, and might make us wonder about other middle-class, university towns or cities in Latin America.

The t-shirt girl foregrounds the idea of resistance and the possibility of constructing her own identity, and de-emphasizes structural and social constraints. Like the student poet, the t-shirt girl uses intertextual discursive resources of the contact zone to parody gender norms, just as other t-shirt wearers parody other phenomena of contact at the bi-national and global levels. While the t-shirt girl is not mentioned directly in the student poem, her voice is noticeably present in the local context, and her t-shirt text can be seen as a parallel move to assert a voice against standard gender norms, even though she picks different points to resist against and brings an entirely different perspective to the textual act.

\section{Bar flyers: language, ethnicity, and gender}

The poet and the t-shirt wearer may frequently walk past one another in the small downtown of Guanajuato, and if they were to enter a specific space in which foreigners and locals mingle, it would probably be in one of the many small

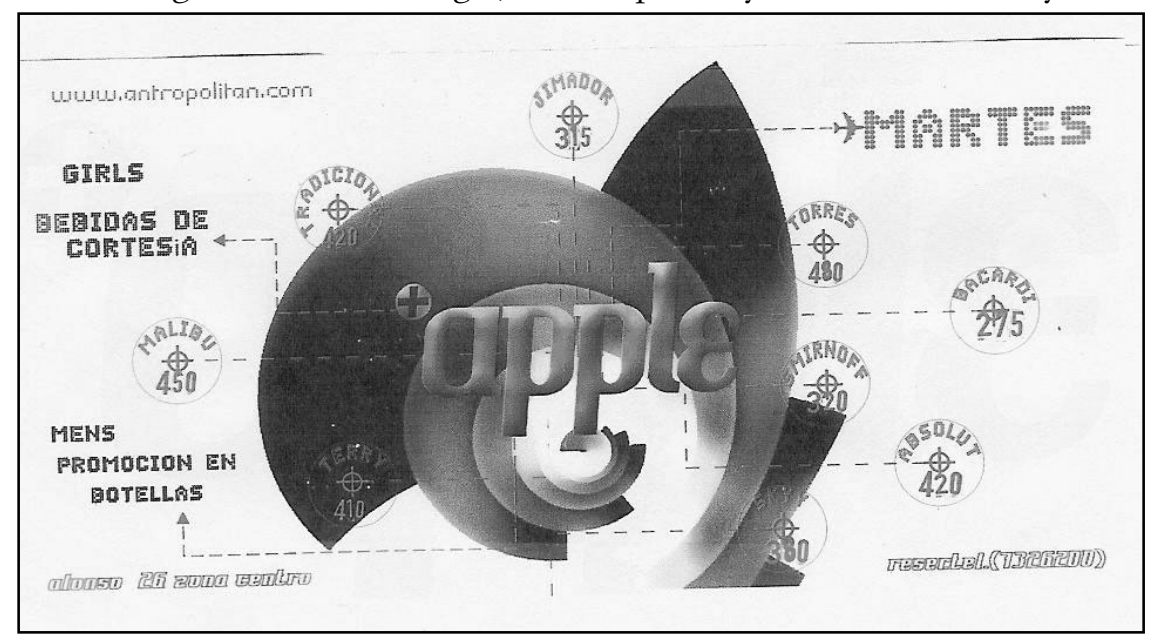


bars in the city center that are geared towards young adults. (The piropo-giver, one might note, they would only encounter on the way home afterwards. ${ }^{10}$ )

This brings us to our article's final genre of text: the computer-produced, bar flyer. These small pieces of paper are handed out by bar staff in the evenings on the streets of the main downtown area. The flyers typically include the bar name, any bargains or specials on drinks, and references to any entertainment A look at just one, leads us to the final points about the ambiguous nature of identity and textual positioning in the contact zone of Guanajuato.

There is a definite and unresolved dialogue between the modern and the traditional in several elements here. In the top left corner is a web address for the bar, which, in and of itself, signals an urban, modern identity, and is strangely, easier to read than the street address. However, this is less odd if you know how small Guanajuato is and how irrelevant addresses are in this twisting, signless city. The first part of the word antropolitan, "antro" which now means "a bar," was until quite recently associated with places of vice, cantinas of ill repute. Here it is meshed with "metropolitan" thus reinforcing general urbanness while referencing the traditional antro of old. ${ }^{11}$

The small bubbles around the computer-generated logo further indicate this "Mexican and modern at once" theme because they include brand names of liquor that are local (Jimador, a Guanajuato tequila), national (Torres, a Mexican brandy), and international (Smirnoff, Absolut).

The use of English on the flyer leans towards the modern since it does not serve any functional, translating purpose; it is a posturing of modern identity. The grammatically incorrect use of "Mens" instead of "men" serves as a good example of naco - failed attempt at being modern — behavior, although this is common in all types of local texts. Apple, the name of the bar, is also in English and probably connotes the Apple computer brand, and not the Big Apple or an American apple pie, although here again, there is opportunity for a multiplicity of readings.

Finally, turning to the gender-related messages in the text, we see a more traditional positioning of men and women. However given the rudimentary English usage, there is an overlap, or perhaps a gap, here too. The word "Girls" is positioned next to "Mens," which does not correspond to English word choice, where one would expect to see the juxtapositions of girls/boys or women/men. This places women in an inferior, child-like position, even while using English, the globally-dominant language, which should, in theory connote modern liberal view of gender relations. Furthermore, women are offered "bebidas de cortesía," courtesy drinks, which implies two things. First, women should be treated 
courteously, which follows tradition (men are courtly and women are courted) and could be aligned with the original piropo era. Second, in this flyer, women have drinks (prepared mixed drinks) while men are offered a "promoción en botellas," or deals on full bottles of hard liquor. This corresponds to traditional images of men as heavy drinkers who skip the pretense of ordering single drinks and go straight for the whole bottle.

The mixed textual messages and heteroglossia present on this flyer point to the ambiguous nature of national and gender identities in Guanajuato. The flyer resists othering processes from the US that would characterize Guanajuato as non-global and non-modern in contrast to its more globalized, high-tech identity. At the same time, the flyer asserts a Mexican identity in the face of external cultural incursions. Contact zone writing strategies such as biculturalism, bilingualism, use of the vernacular and mediation, are all represented here and offer us insight into the ongoing, onsite struggle to make meaning and create identity through encounters with cultural difference.

\section{Conclusion: Coming Backto Intertextuality, Self and 0 ther, and the Contact Zone}

Guanajuato, like most places in which our students study, is textually rich and complex. The student poem, the naco t-shirt, and the bar flyer all dip into the discursive resources of the contact zone and together display an intertextuality that allows us to connect what we often view in isolation - a piece of a student's study abroad experience — with the writing, reading, and thinking of other local community members.

Intertextuality then, for this author, is about agency, something we occasionally forget to assign to onsite cultural others. The student-poet, the t-shirt girl, and the bar flyer producers may draw on the words of others; however they write or use text for their own purposes. All three are actively writing themselves into the social text instead of fitting quietly into some perceived status quo of the local intercultural scene.

A US reading of the student poem that emphasizes the ways in which gender inscribes the study abroad experience is highly relevant and urgently needed. However, this article has tried to show that this is only one interpretation with one set of implications for study abroad professionals. The notion of intertextuality steers us away from the small albeit critical lens with which we tend to analyze student writing, and by extension, student experience. It opens our eyes to the idea that there are other possible readings of student texts with which we could engage in dialogue with local others. 
Thinking intertextually helps to unsettle what Derrida has termed the "violent hierarchies" of binary ways of seeing - in our examples, male-female, foreigner-native, home-abroad, modern-traditional. If these categories that inform so much of our work can be shown to be fluid and unstable, we can then view the meaning of texts (be they student work, local texts, or other cultural artifacts and events) as equally unstable and multiple. Such an approach also invites the consideration of the reader, the act of reading, and local contexts of time and place.

To acknowledge these other perspectives from which to read our students' writing works against the idea that there is only one vantage point from which to view the world, which is the primary purpose of study abroad as an educational endeavor. Intertextuality is but one way to realize these goals.

\section{Not es}

${ }^{1}$ The author wishes to thank Michaela Jeantete for her generous permission to use this poem, for her friendship, and for an ongoing dialogue about poetry writing.

${ }^{2}$ Warshauer Freedman and Ball (2004: 7) cite a reference in Bakhtin's work to a contact zone, although he uses it to mean any site where authority is struggled over. Pratt's use is much more specific and defined in terms of cultural differences and colonialism. This paper will follow Pratt's use of the term, even while drawing on Bakhtin's contributions to the notion of intertextuality.

${ }^{3}$ Guanajuato is the currently the state which sends the most migrants to the US; both Guanajuato-capital and the city of San Miguel de Allende are also sites of some emigration from the US. San Miguel is a longstanding American enclave, while Guanajuato receives (in much smaller numbers) American academics, symphony-members, and retirees, among others.

${ }^{4}$ The terms "othering" and "to other" are widely used in social science and literary analysis, and should be distinguished from the idea of representing. Following Stuart Hall, Representation: Cultural Representations and Signifying Practices (1997), to represent is to use language, symbols or images to stand in for people, ideas, etc. Holliday, Hyde, and Kullman, in Intercultural Communication: An Advanced Resource Book, (2004, p.3), define otherization as "imagining someone as alien and different to 'us' in such a way that 'they' are excluded from our 'normal', 'superior' and 'civilized' group." To other someone is to distance them from the self, and othering thus refers to the process of constructing this distance. In a contact zone, othering happens from multiple points and power positions simultaneously 
${ }^{5}$ Even Bakhtin's ideas are not fully his. Some of the work attributed to him was either written by or written under the names of two of his contemporaries, Volosinov and Medvedev.

${ }^{6}$ This alludes to the social and historical situatedness of texts. Bakhtin wrote against Saussurian views of language use as having meaning within a fixed system, and argued instead that the meaning of language was to be found in the context(s) in which it was used.

${ }^{7}$ This is one feminist and postcolonial critique of the "Death of the Author" position. Some marginalized populations desperately need to become recognized as writers to break imposed silences. While this article chooses not to focus on the student-writer in order to emphasize context and other voices, I would argue strongly in favor of seeing more work on the student experience from students' diverse viewpoints.

${ }^{8}$ One possible origin of the naco t-shirts is with $\mathrm{NaCo}$, a company founded in 2001 by Eduardo Chavarín and Robby Vient, two Mexicans who met at an art school in Pasadena, California. The shirts now sell in California, Arizona, Florida and Illinois - which alludes to the larger context of contact - not to mention in Mexico, and are worn by students, pop stars and others. (http://www. chidochido.com/empezar.html?session=1141168130339). In Guanajuato, the Xperma brand (which is made in Mexico) dominates, and clerks at local stores attest to the rapid turnover in t-shirt designs, which shows how widely this genre is being both produced and consumed since slogans do sell out regularly. The brand-name Xperma that is accompanied by a small sperm icon probably reflects a Spanish text-messaging style of writing which gives it an interesting sheen of modernity.

${ }^{9}$ Since this writing, a national-level sexual education program has been formally proposed; however as of this date (October 2006), it has not been formally approved.

${ }^{10}$ Again, this article refers specifically to Guanajuato and may not reflect what occurs with piropos and piropo-givers in other places in Mexico or Latin America.

${ }^{11}$ The message that Guanajuato is Mexican and modern at once been a key part of larger Mexican discourse promoted domestically and abroad since the 1940's, when tourism became a major source of national income (Saragoza, 2001). 


\section{$R$ ef e r e n c e s}

Allen, G. (2000). Intertextuality. London and New York: Routledge.

Anderson, A. (2003). Women and Cultural Learning in Costa Rica: Reading the Contexts. Frontiers: The Interdisciplinary Journal of Study Abroad (IX), 21-52.

Bakhtin, M.M. (1981). The Dialogic Imagination. Four Essays. Ed. M. Holquist. Trans.C. Emerson \& M. Holquist. Austin: University of Texas Press.

Bauman, R. (2004). A World of Others' Words: Cross-Cultural Perspectives on Intertextuality. Malden, MA: Blackwell Publishing.

Barthes, R. (1974). S/Z. New York: Hill and Wang.

(1977a). Death of the Author. Image, Music, Text. Retrieved 9 October, 2005, from http://faculty.smu.edu/dfoster/theory/Barthes.htm

(1977b). From Work to Text. Image, Music, Text. Retrieved 6 February, 2006, from http://homepage.newschool.edu/ quigleyt/vcs/bartheswt.html

Bazerman, C. (2004). Intertextualities: Volosinov, Bakhtin, Literary Theory, and Literacy Studies. In Ball and Freedman (Eds.), Bakhtinian Perspectives on Language, Literacy, and Learning (pp. 53-65). Cambridge: Cambridge University Press.

Collier, M.J., Ed. (2001). Constituting Difference Through Discourse. Thousand Oaks and London: Sage Publications.

Fairclough, N. (2003). Analysing Discourse: textual analysis for social research.

Fox, N. (1995). Intertextuality and the Writing of Social Science Research. Electronic Journal of Sociology, Vol. 1, No. 2. Retrieved 2 Aug., 2005, from http://www.sociology.org/content/vol001.002/fox.html?PHPSESSID=ba 8192312ab3924b4af6d6f1133808bf

Freedman, S. and Ball, A. (2004). Ideological Becoming: Babktinian Concepts to Guide the Study of Language, Literacy, and Learning. In Ball and Freedman (Eds.), Bakhtinian Perspectives on Language, Literacy, and Learning (pp. 3-33), Cambridge: Cambridge University Press.

García Canclini, N. (1993). Transforming Modernity: Popular Culture in Mexico. Austin: University of Texas Press.

Gee, J. P. (1999). An Introduction to Discourse Analysis. London and New York: Routledge.

Gilbert, J., Rubenstein, A., \& E. Zolov (2001). Fragments of a Golden Age: The Politics of Culture in Mexico Since 1940. Durham and London: Duke University Press. 
Kramsch, C. (1993). Context and Culture in Language Teaching. Oxford: Oxford University Press.

Kristeva, J. (1980). Word, Dialogue, and the Novel. Desire in Language: a semiotic approach to literature and art. New York: Columbia University Press.

Lomnitz-Adler, C. (2001). Deep Mexico, Silent Mexico: An Anthropology of Nationalism. Minneapolis and London: University of Minnesota Press.

Monsiváis, C. (1997). Mexican Postcards. London and New York: Verso.

Moon, D. (2001). Interclass Travel, Cultural Adaptation, and "Passing" as a Disjunctive Inter/Cultural Practice. In Collier, M.J. (Ed.) Constituting Difference Through Discourse (pp. 215-240). Thousand Oaks and London: Sage Publications.

Polanyi, L. (1995). Language Learning and Living Abroad: Stories from the Field. In Freed (Ed.), Second Language Acquisition in a Study Abroad Context (pp. 271-291). Amsterdam/Philadelphia: John Benjamins Publishing Company.

Pratt, M. L. (1999). Arts of the Contact Zone. From Bartholomae and Pretroksky (Eds.), Ways of Reading, 5th Edition. New York: Bedford/St. Martin's. Retrieved 10 Dec., 2000, from http://web.nwe.ufl.edu/ stripp/2504/pratt. html

Saragoza, A. (2001). The Selling of Mexico: Tourism and the State: 1929-1952. In Joseph, G., Rubenstein, A. \& Zolov, E. (Eds). Fragments of a Golden Age: The Politics of Culture in Mexico Since 1940.

Stavans, I. (1990). The Riddle of Cantinflas. Albuquerque: University of New Mexico Press.

Talburt, S. and M. Stewart. (1999). What's the subject of study abroad?: race, gender, and 'living culture. The Modern Language Journal 83(2), p. $163-75$.

Twombly, S. (1995). Piropos and Friendships: Gender and Culture Clash in Study Abroad. Frontiers: The Interdisciplinary Journal of Study Abroad, Vol. I. 
